\title{
An Attempt to Correct Errors of the Sounding Caused by Wire Inclination*
}

\author{
By \\ Toshiyuki Hirano \\ (Tokai Regional Fisheries Research Laboratory)
}

\begin{abstract}
It has been well admitted in oceanographical surveys that a reading of the wire-gauge does not always indicate the true depth of a sounding layer because of inclination of the sounding wire caused by ocean currents and winds. In order to correct errors resulted from the slope of the wire the writer has made an attempt to estimate curving patterns of the sounding wire under water and to draw the correcting curves, using data on the falling velocity of a messenger, which was obtained by Watanabe (1943), on the basis of the equation of motion of a naturally falling body.

It is hoped that this attempt would be of help for drawing some more correcting curves with better accuracy.
\end{abstract}

\section{§1. Introduction}

When carrying out the oceanographical surveys, a reading of the wire-gauge does not always indicate the true depth of a sounding layer because of inclination of the sounding wire caused by ocean currents and winds. Many papers have been published in regard to various methods in the effort to correct errors resulted from the slope of the wire. The writer has made an attempt to estimate curving patterns of the sounding wire under water and to correct errors of the sounding, using data on the falling velocity of a messenger obtained by Watanabe (1943) in the oceanographical observations of the Japan Sea in May and June, 1941.

\section{The equation of motion of the messenger falling under water}

i) The motion of a messenger falling down along the sounding wire can be regarded to approximate the motion of the falling body along a wire under water on which only gravity acts, providing that the friction between the wire and the messenger is negligibly small. Then the equation of motion is approximately written by

$$
m \frac{d v}{d t}=m g \cos \theta-\kappa v^{2},
$$

where $v$ is the velocity of the messenger along the wire, $t$ the time, $\kappa$ the

* Contributions from. Tokai Regional Fisheries Research Laboratory B No. 91. 
coefficient of the viscosity resistance, $m$ the mass of the messenger, $g$ the acceleration of gravity, and $\theta$ the angle of inclination. (But, in an exact sense, $\theta$ is the function of depth.)

ii) In the observation on board, as a messenger is sent from some hights above the surface (from a hight of $2 \mathrm{~m}$ in the Soyo-maru), it falls through the air until reaching the sea surface. In such a case, assuming $\kappa \fallingdotseq 0$, the equation (1) is

$$
\frac{d v}{d t}=g \cos \theta
$$

In the case of natural falling, solving the equation (2), the velocity $\bar{v}$ of the messenger being about to dive into water is

$$
\bar{v}=\sqrt{2 \bar{S} g \cos \theta},
$$

where $\bar{S}$ is the length of the wire from the starting point of the messenger to the sea surface, providing that $\theta$ is constant.

iii) Next, if the messenger is falling with a uniform velocity after passing a certain length of the wire the equation (1) is

$$
m g \cos \theta-\kappa v^{2}=0 \text {. }
$$

Now, putting $K=\frac{\kappa}{m}$, from the equation (4) the terminal velocity $v$ of the falling messenger is expressed by

$$
v=\sqrt{\frac{g \cos \theta}{K}} .
$$

iv) From the equation (1) under the fact that the falling messenger must have passed the $S$ length from the surface to a certain point along the wire for the time $t, S$ is formulated

$$
S=\frac{1}{K} \log \frac{\bar{v}-v}{2 v}\left(\frac{\bar{v}+v}{\bar{v}-v} \exp (v K t)-\exp (-v K t)\right),
$$

where $\theta$ is assumed to be constant, but in an exact sense, the function of $S$.

\section{§3. Calculation and discussion on the Value of $K$}

Supposing $\cos \theta \fallingdotseq 1$ when the angle of the wire inclination is $0^{\circ} \sim 9^{\circ}$, it is deduced from Table 1 that the average time required for the messenger in travelling along the wire in depths more than 100 meters from the surface is about $23.5 \mathrm{sec}$ per 100 meters until reaching the end of the wire. Because, as indicated in Table $]$,

$$
\begin{aligned}
46.9 \mathrm{sec}-23.4^{b)} \mathrm{sec} & =23.5 \mathrm{sec} \\
\frac{117.5 \mathrm{sec}-46.9 \mathrm{sec}}{3} & =23.53 \mathrm{sec}
\end{aligned}
$$


T. Hirano: An Attempt to Correct Errors.

Table 1. Number of observations, average, maximum and minimum of time required in falling of the messenger No. 6 * $^{*}$

\begin{tabular}{|c|c|c|c|c|c|c|}
\hline $\begin{array}{l}\text { Interval } \\
\text { of wire }\end{array}$ & $\begin{array}{l}\text { Inclination } \\
\text { Time }\end{array}$ & $0^{\circ}-9^{\circ}$ & $10^{\circ}-19^{\circ}$ & $20^{\circ}-29^{\circ}$ & $30^{\circ}-39^{\circ}$ & $40^{\circ}-49^{\circ}$ \\
\hline$\left.\right|_{100} ^{0 \mathrm{~m}}$ & $\begin{array}{l}21 \text { sec } \\
22 \\
23 \\
24 \\
25\end{array}$ & $\begin{array}{r}1 \\
1 \\
31 \\
8 \\
3\end{array}$ & $\begin{array}{r}\frac{1}{13} \\
11 \\
3\end{array}$ & $\begin{array}{l}- \\
\overline{6} \\
7\end{array}$ & $\frac{-}{\overline{1}}$ & $\begin{array}{c}- \\
- \\
-\end{array}$ \\
\hline \multicolumn{2}{|c|}{ Average time } & 23.4 & 23.5 & 24.5 & 24.8 & - \\
\hline \multicolumn{2}{|c|}{ Maximum \& minimum } & $25 \sim 21$ & $25 \sim 21$ & $25 \sim 24$ & $25 \sim 24$ & - \\
\hline $0 \mathrm{~m}$ & $\begin{array}{l}44 \mathrm{sec} \\
45 \\
46 \\
47 \\
48 \\
49 \\
50 \\
51 \\
52 \\
53 \\
54 \\
55 \\
56 \\
57\end{array}$ & $\begin{array}{l}1 \\
2 \\
4 \\
8 \\
2 \\
1 \\
- \\
- \\
- \\
- \\
-\end{array}$ & $\begin{array}{l}1 \\
1 \\
6 \\
5 \\
3 \\
2 \\
- \\
- \\
- \\
- \\
-\end{array}$ & $\begin{array}{l}- \\
- \\
3 \\
3 \\
6 \\
1 \\
2 \\
1 \\
1 \\
- \\
- \\
-\end{array}$ & $\begin{array}{l}- \\
- \\
- \\
\overline{1} \\
2 \\
1 \\
1 \\
\frac{1}{-} \\
-\end{array}$ & $\begin{array}{l}- \\
- \\
\overline{-} \\
\overline{-} \\
1 \\
\frac{1}{\overline{1}} \\
\frac{1}{1} \\
1\end{array}$ \\
\hline \multicolumn{2}{|c|}{ Average time } & 46.9 & 47.7 & 49.2 & 51.7 & 53.6 \\
\hline \multicolumn{2}{|c|}{ Maximum \& minimum } & $52 \sim 44$ & $50 \sim 44$ & $53 \sim 47$ & $54 \sim 49$ & $57 \sim 50$ \\
\hline $\begin{array}{l}0 \mathrm{~m} \\
\\
500\end{array}$ & $\begin{array}{l}115 \mathrm{sec} \\
116 \\
117 \\
118 \\
119 \\
120 \\
121 \\
122 \\
123 \\
124 \\
125 \\
126 \\
127 \\
128 \\
129 \\
130 \\
131 \\
132 \\
133 \\
134 \\
135 \\
136\end{array}$ & $\begin{array}{l}3 \\
2 \\
5 \\
1 \\
4 \\
1 \\
-1 \\
= \\
= \\
= \\
= \\
= \\
= \\
= \\
= \\
-\end{array}$ & $\begin{array}{l}- \\
= \\
33 \\
1 \\
1 \\
2 \\
5 \\
-1 \\
- \\
- \\
- \\
- \\
- \\
- \\
- \\
-\end{array}$ & $\begin{array}{l}- \\
-1 \\
- \\
1 \\
3 \\
1 \\
1 \\
1 \\
- \\
1 \\
- \\
- \\
- \\
- \\
- \\
-\end{array}$ & $\begin{array}{l}- \\
- \\
- \\
- \\
1 \\
- \\
2 \\
2 \\
1 \\
1 \\
1 \\
1 \\
= \\
- \\
- \\
- \\
-\end{array}$ & $\begin{array}{l}- \\
= \\
= \\
= \\
= \\
= \\
= \\
= \\
1 \\
= \\
= \\
= \\
1 \\
1\end{array}$ \\
\hline \multicolumn{2}{|c|}{ Average time } & 117.5 & 121.2 & 122.5 & 124.6 & 130.7 \\
\hline \multicolumn{2}{|c|}{ Maximum \& minimum } & $122 \sim 115$ & $128 \sim 118$ & $128 \sim 117$ & $129 \sim 120$ & $136 \sim 125$ \\
\hline
\end{tabular}

* Source: Shisui No. 6 no rakka shoyojikan no kansoku kaisuu, saidaichi to saishochi oyobi heikin rakka shoyojikan, translated as above; Watanabe (1943). 
a) The average time required from the surface to a depth of $200 \mathrm{~m}$.

b) The average time required from the surface to a depth of $100 \mathrm{~m}$.

c) The average time required from the surface to a depth of $500 \mathrm{~m}$.

Using the value of the time requirea in falling of the messenger for a length of 100 meter, $K$ is deduced from the equation (5)

$$
K=\frac{g}{\boldsymbol{v}_{0}^{2}}=\frac{980}{\left(\frac{10000}{23.5}\right)^{2}} \fallingdotseq 54.12 \times 10^{-4}
$$

where $\boldsymbol{v}_{0}$ is the terminal velocity when the wire inclination is 0 .

In the above calculation we have roughly obtained the value of $K$ by use of the data shown in Table 1. However, we must discuss whether the equation' (1) would satisfy the case of our problem, and whether the value of $\kappa$ in the equation (1) is probable.

Fig. 1. The messenger No. 6 .

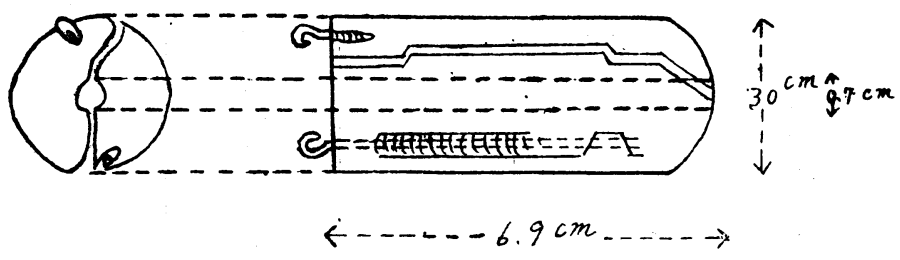

$4.0 \mathrm{~cm}$

As shown in Fig. 1, the messenger No. 6 may be regarded as a cylinder of which the sectional area is $\frac{\pi}{4}\left(3^{2}-0.7^{2}\right) \mathrm{cm}^{2}$, the length $6.9 \mathrm{~cm}$, and the mass $321 \mathrm{~g}$. Now the falling velocity of this messenger may be estimated about 10000/25 $\mathrm{cm} / \mathrm{sec}=400 \mathrm{~cm} / \mathrm{sec}$ on the basis of Table 1 . Assuming the kinematic viscosity $\nu$ of sea water be about $0.013\left[L^{2} T^{-1}\right]$, Reynolds' number is

$$
R=\frac{d \cdot v}{\nu}=\frac{12}{13} \times 10^{5},
$$

where $d$ is the diameter of the messenger.

When the messenger is regarded as a cylinder, it is considered on the basis of experiments that the coefficient of the viscosity resistance to the values (the order of $10^{5}$ ) of Reynolds' number is almost constant, and that the resistance force is proportioned to a square of the velocity $v$. The resistance force $D$ is generally.

$$
D=\frac{\rho}{2} v^{2} c_{x} \frac{\pi}{4} d^{2}
$$

where $c_{x}$ represents the coefficient of the resistance and is considered about 0.85 in the case of a cylinder such as the messenger No. 6, and where $\rho$ the density. of sea water. 
T. Hirano: An Attempt to Correct Errors.

$K$ is calculated from the equation (8) as :

$$
K=\frac{\kappa}{m}=\frac{\rho}{2} c_{x} \cdot \frac{\pi}{4} \frac{d^{2}}{m} \fallingdotseq 91 \times 10^{-4} .
$$

When compared the value of $K$ obtained above with that of the equation (7), they belong to the same order, but do not agree in the values. This difference in the values of $K$ themselves may be resulted by the fact that the messenger has been regarded as a cylinder, and that the messenger slides down the wire (see: Ōyō Ryūtairikigaku, Applied Hydrodynamics, by B. Fujimoto).

\section{§. Estimation on curving patterns of the sounding wire under water.}

i) The falling velocity of the messenger is considered uniform under water deeper than 100 metetrs in the case of the sounding wire being inclined at $0^{\circ} \sim 9^{\circ}$. Therefore, let us assume that the falling velocity of the messenger is also approximately uniform in the wire inclination at $\theta$, and that the sounding wire keeps a constant inclination in a straight line from a $100 \mathrm{~m}$ depth to a $200 \mathrm{~m}$ depth and from a $200 \mathrm{~m}$ depth to a $500 \mathrm{~m}$ depth. Consequently by means of the equations (5) and (7)

$$
\begin{gathered}
\boldsymbol{v}^{2}=\boldsymbol{v}_{0}^{2} \cos \theta \\
\therefore \quad \theta=\cos ^{-1}\left(\frac{\boldsymbol{v}}{\boldsymbol{v}_{0}}\right)^{2} .
\end{gathered}
$$

Thus, we can calculate numerical values of $\theta$ from values of $\boldsymbol{v}_{0}$ and respective $\boldsymbol{v}$ obtained by the above assumptions and data. If it takes time $\tau_{0}$ and $\tau$ respectively when the messenger falls at velocities of $\boldsymbol{v}_{0}$ and $\boldsymbol{v}$ for a depth of $100 \mathrm{~m}$, the equation (9) is

$$
\theta=\cos ^{-1}\left(\frac{\tau 0}{\tau}\right)^{2}=\cos ^{-1}\left(\frac{23.5}{\tau}\right)^{2}
$$

ii) As the falling messenger cannot be supposed to have a uniform velocity as far as a depth of about 100 meters from the surface, we have to adopt the equation (6). Estimating $t \fallingdotseq 23 \mathrm{sec}$ in the term $\exp (-\boldsymbol{v} K t)=e^{-\sqrt{g K} \cos \theta} t$ in the equation (6), vKt may approximate to 121.7. Therefore, let us neglect the term $\exp (-v K t)$ in the equation (6), then

$$
\begin{gathered}
S=\frac{1}{K} \log \frac{\bar{v}-v}{2 v}\left(\frac{\bar{v}+v}{v-v} \exp (v K t)\right) \\
\therefore S K=\log \frac{\bar{v}+v}{2 v}+v K t .
\end{gathered}
$$

From the equations (3) and (5) 


$$
\left.\begin{array}{l}
\bar{v}=\sqrt{2 \bar{S} \cdot g} \sqrt{\cos \bar{\theta}}=\bar{v}_{0} \sqrt{\cos \bar{\theta}} \\
v=v_{0} \sqrt{\cos \theta}
\end{array}\right\}
$$

where $\bar{v}_{0}=\sqrt{2 \bar{S} \cdot g}$ is the velocity of the messenger being about to dive into water when the inclination of the sounding wire is zero, and where $\bar{\theta}$ is the wire inclinaction with which the messenger drops through the air.

Now, assuming $\sqrt{\cos \bar{\theta}} \fallingdotseq \sqrt{\cos \theta}$,

$$
\frac{\bar{v}+v}{2 v}=\frac{\bar{v}_{0}+v_{0}}{2 v_{0}}
$$

Then the equation (11) is

$$
\theta=\cos ^{-1}\left(\frac{S K-\log \frac{\bar{v}_{0}+v_{0}}{2 v_{0}}}{K v_{0}} \frac{1}{t}\right)^{2} .
$$

Using the equations (10) and (12), values of the wire inclination $\theta$ for depths at each interval which correspond to the wire inclinations of the surface are obtained by the average values of the time required in falling of the messenger

\begin{tabular}{|c|c|c|c|c|c|c|c|c|c|c|c|}
\hline $\begin{array}{l}\text { Wire inclination } \\
\text { at the surface }\end{array}$ & \multicolumn{3}{|c|}{$10^{\circ} \sim 19^{\circ}$} & \multicolumn{3}{|c|}{$20^{\circ} \sim 29^{\circ}$} & \multicolumn{3}{|c|}{$30^{\circ} \sim 39^{\circ}$} & \multicolumn{2}{|c|}{$40^{\circ} \sim 49^{\circ}$} \\
\hline $\begin{array}{l}\text { Depth read by } \\
\text { gauge }\end{array}$ & or $\mathrm{m}$ & $\mid \begin{array}{cc}100^{\mathrm{m}} \\
\sim 200\end{array}$ & $\begin{array}{r}200^{\mathrm{m}} \\
\sim 500\end{array}$ & $\begin{array}{r}\mathrm{m} \\
0 \sim 100\end{array}$ & $\left|\begin{array}{cc}100 & \mathrm{~m} \\
\sim 200\end{array}\right|$ & $\begin{array}{r}200^{\mathrm{m}} \\
\sim 500\end{array}$ & $\begin{array}{r}\mathrm{m} \\
0 \sim 100\end{array}$ & $\left|\begin{array}{cc}100^{\mathrm{m}} \\
\sim 200\end{array}\right|$ & $\begin{array}{r}200^{\mathrm{m}} \\
\sim 500\end{array}$ & $\mid \begin{array}{r}m \\
0 \sim 200\end{array}$ & $\begin{array}{r}200^{\mathrm{m}} \\
\sim 500\end{array}$ \\
\hline $\begin{array}{l}\text { Average time in } \\
\text { falling } 100 \mathrm{~m}\end{array}$ & $\begin{array}{c}\mathrm{sec} \\
23.5\end{array}$ & $\begin{array}{c}\mathrm{sec} \\
24.2\end{array}$ & $\begin{array}{c}\mathrm{sec} \\
24.5\end{array}$ & $\begin{array}{c}\mathrm{sec} \\
24.5\end{array}$ & $\begin{array}{r}\mathrm{sec} \\
24.7\end{array}$ & \begin{tabular}{|c|}
$\mathrm{sec}$ \\
24.4
\end{tabular} & $\begin{array}{c}\mathrm{sec} \\
24.8\end{array}$ & $\begin{array}{c}\sec \\
26.9\end{array}$ & $\begin{array}{c}\mathrm{sec} \\
24.3\end{array}$ & $\begin{array}{r}\mathrm{sec} \\
(53.6)^{*}\end{array}$ & $\begin{array}{r}\mathrm{sec} \\
25.7\end{array}$ \\
\hline Wire inclination & $18^{\circ} 19^{\prime}$ & $19^{\circ} 26^{\prime}$ & $23^{\circ} 04^{\prime}$ & $29^{\circ} 08^{\prime}$ & $25^{\circ} 09^{\prime}$ & $21^{\circ} 57^{\prime}$ & $31^{\circ} 31^{\prime}$ & $40^{\circ} 15^{\prime}$ & $20^{\circ} 45^{\prime}$ & $41^{\circ} 40^{\prime}$ & $33^{\circ} 16^{\prime}$ \\
\hline
\end{tabular}
('Table 2).

Table 2. Values of the sounding wire inclination for each depth interval.

* Average time required in falling $200 \mathrm{~m}$.

From the values of the wire inclinations under water obtained above, the writer has drawn curving patterns of the sounding wire under water with the solid lines broken at points (Fig. 2) and deduced the correcting curves from these patterns (Fig. 3).

Let us compare these values of the correcting curves with: (A) the correcting values deduced from the cosine calculation; (B) the values of the correcting curves being used by the Hydrographic Office, Maritime Safety Agency, Japan; and (C) the values of the correcting curves obtained by Fukutomi's Method respectively (Table 3 ). The values obtained here fairly agree:

1) at such shallow depths as of 100 and 200 meters, with (A) more than (B) and (C) ; 
Table 3. Comparison of various correcting values for the sounding.

\begin{tabular}{|c|c|c|c|c|c|c|}
\hline \multicolumn{2}{|c|}{$\begin{array}{l}\text { Depth read } \\
\text { by gauge } \\
\text { Inclination } \\
\text { at the surface }\end{array}$} & $100 \mathrm{~m}$ & $200 \mathrm{~m}$ & $300 \mathrm{~m}$ & $400 \mathrm{~m}$ & $500 \mathrm{~m}$ \\
\hline \multirow{4}{*}{$15^{\circ}$} & $\mathrm{A}$ & $3.4 \mathrm{~m}$ & 6.8 & 10.2 & 13.6 & 17.1 \\
\hline & B & 4.0 & 8.0 & 11.5 & 14.0 & 17.0 \\
\hline & C & $\begin{array}{r}\text { approx. } \\
1.0 \\
\end{array}$ & $\begin{array}{r}\text { approx. } \\
2.5 \\
\end{array}$ & 4.0 & 6.0 & 8.0 \\
\hline & $D$ & 4.5 & 10.0 & 18.0 & $\begin{array}{c}26.0 \\
(23.5) \\
\end{array}$ & $\begin{array}{c}34.0 \\
(31.5) \\
\end{array}$ \\
\hline \multirow{4}{*}{$25^{\circ}$} & A & 9.4 & 18.7 & 28.1 & 37.5 & 46.9 \\
\hline & B & 8.0 & 15.3 & 22.0 & 29.0 & 34.5 \\
\hline & C & 3.0 & 7.0 & 12.0 & 16.0 & 21.0 \\
\hline & D & $\begin{array}{c}12.4 \\
(10.0)\end{array}$ & 22.0 & 29.5 & 36.0 & 43.0 \\
\hline \multirow{4}{*}{$35^{\circ}$} & A & 18.1 & 36.2 & 54.2 & 72.3 & 90.4 \\
\hline & B & 12.5 & 24.5 & 365 & 47.0 & 57.0 \\
\hline & $\mathrm{C}$ & 7.0 & 15.0 & 24.0 & 32.0 & 42.0 \\
\hline & D & $\begin{array}{c}\mathbf{1 4 . 0} \\
(16.0)\end{array}$ & $\begin{array}{c}38.0 \\
(35.5) \\
\end{array}$ & 44.0 & 50.0 & 57.0 \\
\hline \multirow{4}{*}{$45^{\circ}$} & A & 29.3 & 58.6 & 87.9 & 117.2 & 146.5 \\
\hline & B & 18.5 & 36.0 & 53.0 & 68.5 & 83.5 \\
\hline & C & 12.0 & 26.0 & 43.0 & 59.0 & 78.0 \\
\hline & D & 24.0 & $\begin{array}{c}48.0 \\
(50.0)\end{array}$ & 63.0 & 75.5 & 93.0 \\
\hline
\end{tabular}

A : The correcting values deduced from the cosine calculation.

B : The values of the correcting curves being used by the Hydrographic Office, Mari. Saf. Agen. Japan.

C : The values of the correcting curve obtained by Fukutomi's method.

D : The values calculated by the falling velocity of the messenger.

2) at depths of 300 meters and deeper, with (A) when the wire is inclined at $25^{\circ}$ on the surface, and with (B) at other inclinations. However,

3 in case of the wire inclination as small as $15^{\circ}$ on the surface, our values are greater than these three values, (A) (B) and (C);

4) the values of (C) in general are so small as compared with the others.

At the end of this paper, the writer wishes to express his hearty thanks to Mr. Watanabe for encouragement and support, and to Dr. H. Miyamoto for valuable suggestions, rendered in carrying out this present work. 
Fig. 2. Patterns of the sounding wire. Solid lines are patterns of the wire for inclinations at $10^{\circ} \sim 19^{\circ}, 20^{\circ} \sim 29^{\circ}, 30^{\circ} \sim$ $39^{\circ}, 40^{\circ} \sim 49^{\circ}$ at the surface; dotted lines are these extended down from the surface with constant inclinations at $15^{\circ}, 25^{\circ}$, $35^{\circ} 45^{\circ}$.

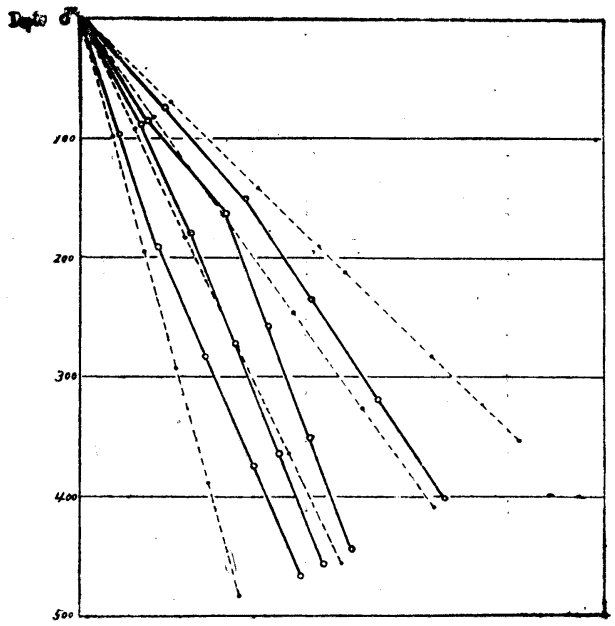

Fig. 3. Correcting curves of the sounding.:

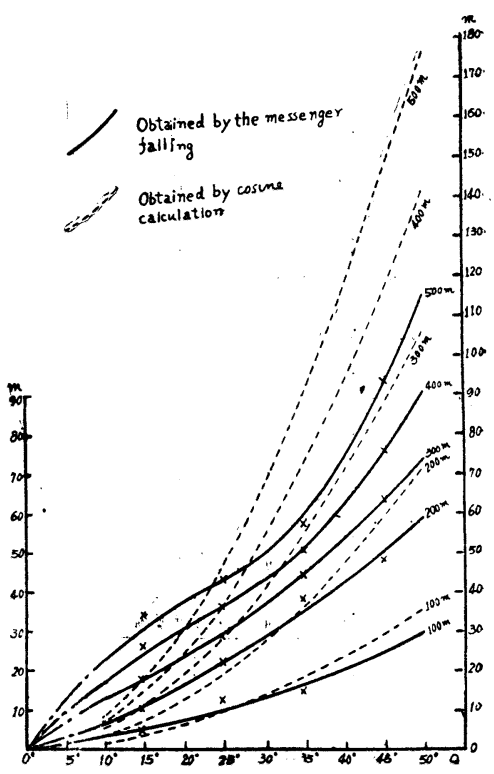

\section{Reference}

(1) Fukutomi, K. 1943: Sokushinkosaku no keisha kara fuuatsuryu matawa kairyu,no kinjiteki-suiteiho. (The method of approximate estimation of the drift or ocean currents by the wire inclination.) Jour. Oce. Soc. Jap. Vol. 2 No. 3.

(2) Hidaka, K. \& Sakata, M. 1942: Suichu ni okeru kosaku no katachi ni tsuite. (On the patterns of the sounding wire under water.) Jour. Oce. Soc. Jap. Vol. 2 No. 1.

(3) Hishida, K. 1949: Suichu ni okeru kosaku no katachi ni tsuite. (On the patterns of the sounding wire under water.) Jour. Oce. Soc. Jap. Vol. 5 No. 1.

(4) Uda, M. 1934: Kosaku no keisha ni yoru sokushin sonota no gosa ni tsuite. (On the errors of the sounding and others caused by the inclination of the sounding wire.) Umi to Sora Vol. 14 No. 4.

(5) Watanabe, N. 1943: Shisui no rakkasokudo no sokutei. (The measurements of the falling velocity of the messenger.) Umi to Sora Vol. 23 No. 6.

(6) Wüst, G.: Thermometrishe Tiefenmessung. Deutsch-Atlantische Expedition "Meteor". Bd. IV Erster Teil. 